\title{
A MATLAB Program for Interaction Curves of Prestressed Concrete Columns with High Tensile Steel Bars
}

\author{
Shinju Sajeev Valaparambil ${ }^{1}$, Sivan P. P², Sanya Maria Gomez \\ 1,3 (Civil Engineering Department, SCMS School of Engineering \& Technology, Ernakulam, Kerala, India) \\ ${ }^{2}$ (Civil Engineering Department, Government Engineering College, Thrissur, Kerala, India)
}

\begin{abstract}
A software program that determines the load-moment interaction diagrams for prestressed concrete short columns stressed with high tensile steel bars is presented. The program solves for all possible variables such as concrete compressive strength, $d / D$ ratio, $B / D$ ratio and percentage steel. Two sets of charts were plotted - (1) Keeping $B=230 \mathrm{~mm}, B / D$ ratios were varied along with variations in concrete compressive strength, d/D ratio and percentage steel. (2) Neutralizing the effect of $B / D$ ratio $\left(\frac{\boldsymbol{M}_{U R}}{f_{c k} \boldsymbol{B D} \boldsymbol{D}^{2}}, \frac{\boldsymbol{P}_{U R}}{\boldsymbol{f}_{\boldsymbol{c} k} \boldsymbol{B D}}\right)$ curves were plotted for different percentage steel varying concrete compressive strength and d/D ratio. A comparison is made between interaction curves of columns stressed with cold drawn wires and high tensile steel bars.
\end{abstract}

Keywords : High tensile steel bars, interaction curves, MATLAB, prestressed column, prestressed compression members

\section{Introduction}

Prestressing has proved to be disadvantageous when columns are subjected to axial compression only. In actual practice a compression member rarely carries pure compression. Columns are normally subjected to bending in addition to axial load, since external loads are rarely concentric. As a result, the concrete section is subjected to tension at the side farthest from the line of action of the longitudinal load. Cracking develops, but it can be prevented through the use of prestress in the columns. One beneficial effect of prestressing a compression member is the reduction of its deflection under transverse loads. Since the deflection of an uncracked section is about $40 \%$ that of a cracked section, a prestressed pylon could be about 2.5 times as stiff as an ordinary reinforced one. In this instance, the reduction of deflection at the top of the pylon minimizes the relative movements between the building floors and saves a tremendous amount of steel otherwise required to reinforce other parts of the building.

It is simple to compute the ultimate $P_{n}$ and $M_{n}$ for a given location of ultimate neutral axis. On the other hand, it would be a major mathematical problem to determine the neutral axis, if either $P_{n}$ or $M_{n}$ or both are given. Thus the resisting capacity of a given section can be best obtained by computing the interaction curve for ultimate $P_{n}$ and $M_{n}$ for various assumed locations of ultimate neutral axis. The equations to develop interaction curves for prestressed concrete short columns were already available. But the easiest and quickest method of using computer software to develop the curves was never observed.

The objective of this paper is to develop interaction curves using MATLAB software for basic prestressed concrete short columns subjected to uniaxial bending and stressed with high tensile steel bars.

\section{Development of Interaction Curves for Prestressed Concrete Columns using MATLAB}

\subsection{MATLAB Program}

As per IS Code, the equations for generating interaction curves of rectangular prestressed short columns were developed by Dr. Amlan. K. Sengupta and Prof. Devdas Menon [2]. These equations were modified and a MATLAB program was generated to plot the interaction curves [1]. Flowcharts of the MATLAB program are shown below. Here, $k_{l}$ represents the smallest positive value of $k$ obtained by equating $P_{U R}$ of case 3 to zero by adopting a particular condition of $\epsilon_{p l}$. Whereas $k_{2}$ is the highest value of $k$, representing case 1 . 

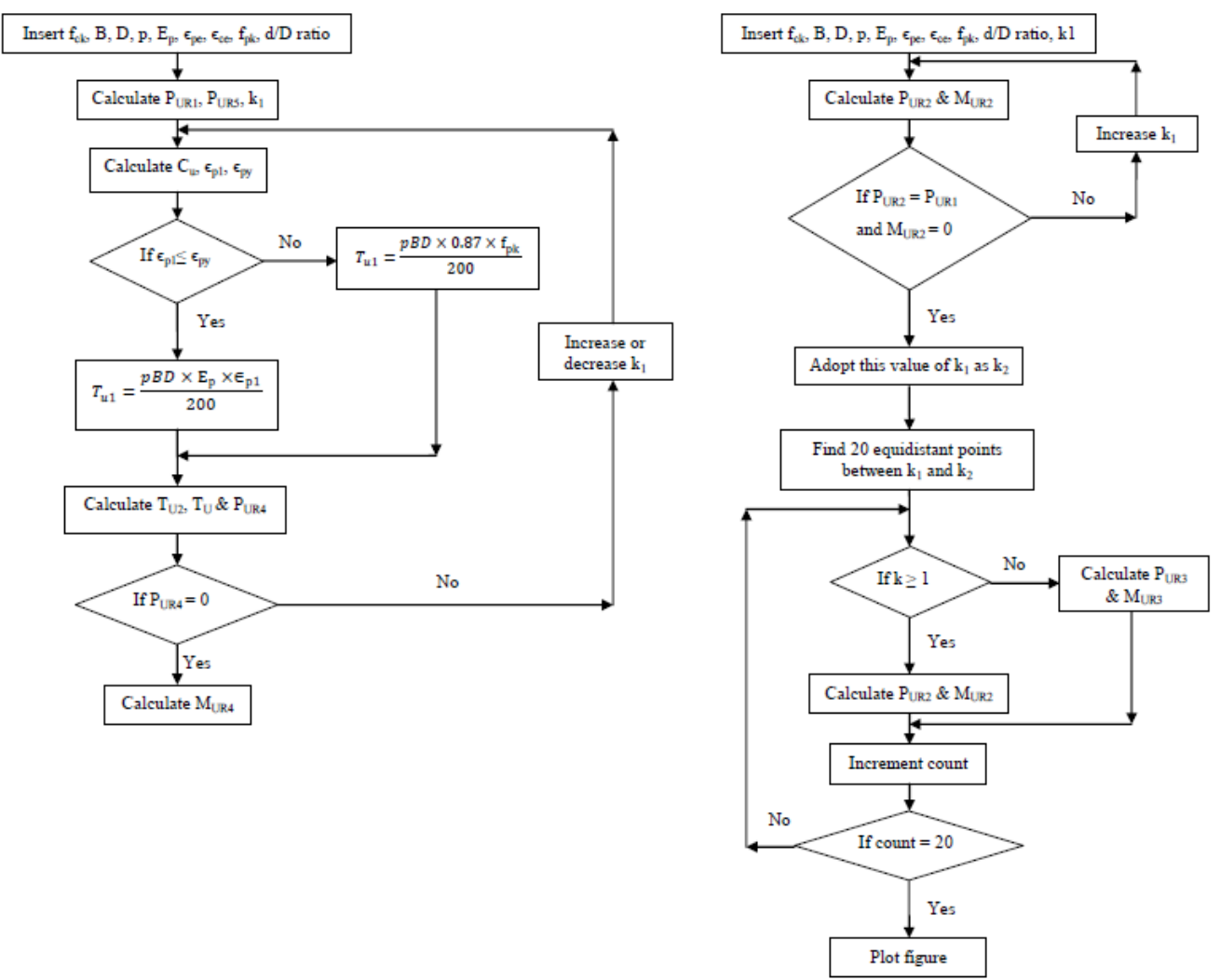

Fig.1. Flowchart for program of case 1 , case $4 \&$ case 5

Fig.2. Flowchart for program of case $2 \&$ case 3

\subsection{Interaction Curves}

The various constants and variables chosen to plot the curves are as follows:

a) Concrete compressive strength : $f_{c k}=40,50 \& 60 \mathrm{~N} / \mathrm{mm}^{2}$

b) Elastic modulus of prestressing steel: As per IS: $1343-1980$, clause $4.5 .3 .1, E_{p}=200000 \mathrm{~N} / \mathrm{mm}^{2}$ [3].

c) d/D Ratio: Various d/D ratios have been chosen.

i) Central prestressing $\left(\frac{d}{D}=0\right)$ ii) Half kern distance $\left(\frac{d}{D}=0.08\right)$

Beyond 0.08, the curves show irregular profile.

d) Tensile strength of prestressing steel: As per IS: $2090-1983, f_{p k}=980 \mathrm{~N} / \mathrm{mm}^{2}$ [4].

e) Cross sectional Dimensions:

$\mathrm{B}=230 \mathrm{~mm}$

$\mathrm{D}=\mathrm{B}, 1.25 \mathrm{~B}, 1.5 \mathrm{~B}, 1.75 \mathrm{~B}, 2 \mathrm{~B}, 2.25 \mathrm{~B}, 2.5 \mathrm{~B}, 2.75 \mathrm{~B}, 3 \mathrm{~B}$

f) Effective prestress: Assuming the loss of prestress as $30 \%, f_{p e}$ is calculated.

Initial stress in wires, $f_{p i}=0.8 f_{p k}$

Loss of stress $=\operatorname{loss} \% \times 0.8 f_{p k}=\frac{30 \times 0.8 \times 980}{100}=235.2 \mathrm{~N} / \mathrm{mm}^{2}$

Effective prestress, $f_{p e}=(0.8 \times 980)-235.2=548.8 \mathrm{~N} / \mathrm{mm}^{2}$

$\epsilon_{p e}=\frac{f_{p e}}{E_{p}}=\frac{548.8}{200000}=0.002744$

$\epsilon_{c e}=\frac{A_{p} \times f_{p e}}{\left(A_{g}-A_{p}\right) E_{c}}\left[1+\frac{e^{2}}{r^{2}}\right]$

where, $r=\sqrt{\frac{I}{A}}$

g) Percentage steel: As per IS: 1343-1980, clause 22.2, minimum percentage steel $=\frac{2.5 \times 100}{f_{p e}}=\frac{2.5 \times 100}{548.8}=0.45 \%$. $p=0.45 \%, 0.6 \%, 0.75 \%, 0.9 \%, 1.05 \%, 1.2 \%, 1.35 \%$ 
The maximum percentage steel is limited to $1.35 \%$, beyond which the curves take a straight line profile. Only certain charts are shown here.
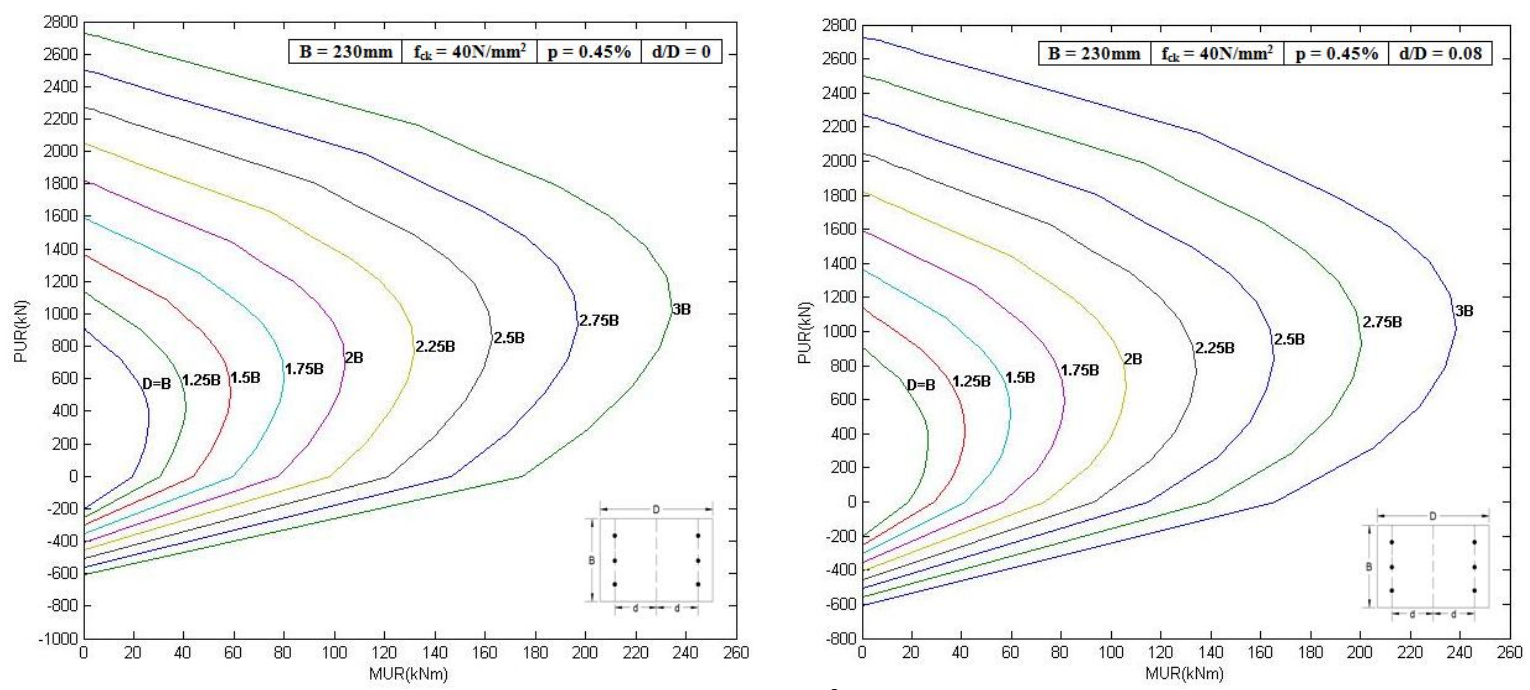

3a. Interaction curves with $\mathrm{fck}=40 \mathrm{~N} / \mathrm{mm}^{2}, \mathrm{p}=0.45 \%$ and varying $\mathrm{d} / \mathrm{D}$ ratio
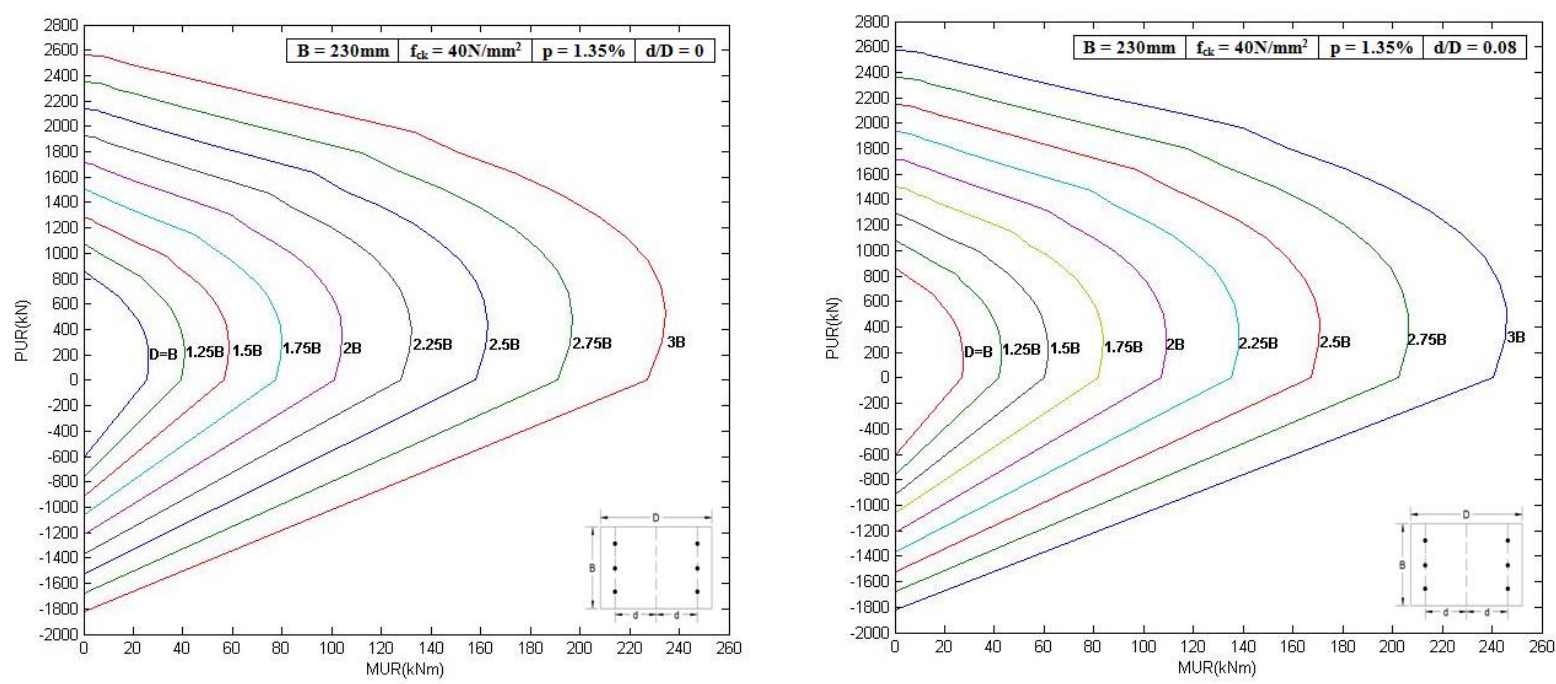

3b. Interaction curves with fck $=40 \mathrm{~N} / \mathrm{mm}^{2}, \mathrm{p}=1.35 \%$ and varying $\mathrm{d} / \mathrm{D}$ ratios
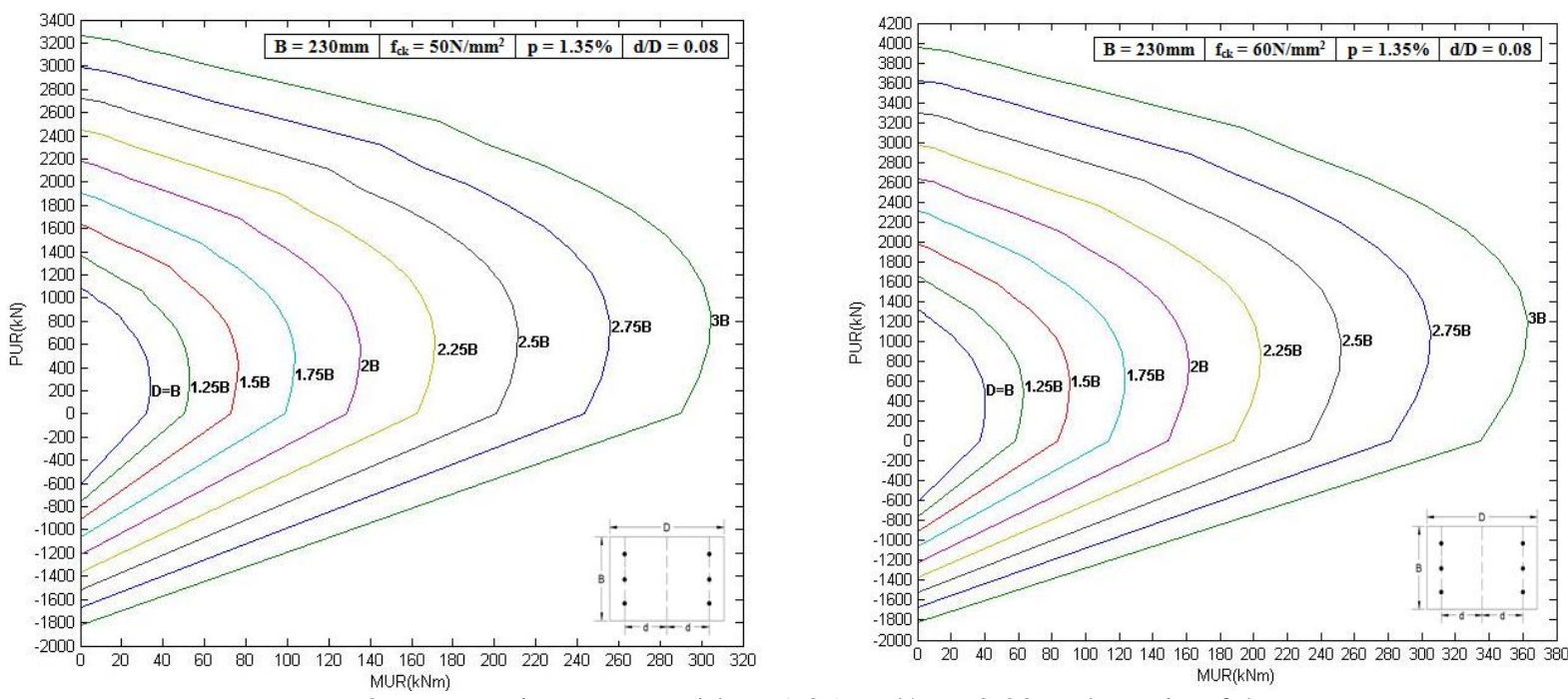

$3 c$. Interaction curves with $\mathrm{p}=1.35 \%, \mathrm{~d} / \mathrm{D}=0.08$ and varying fck 

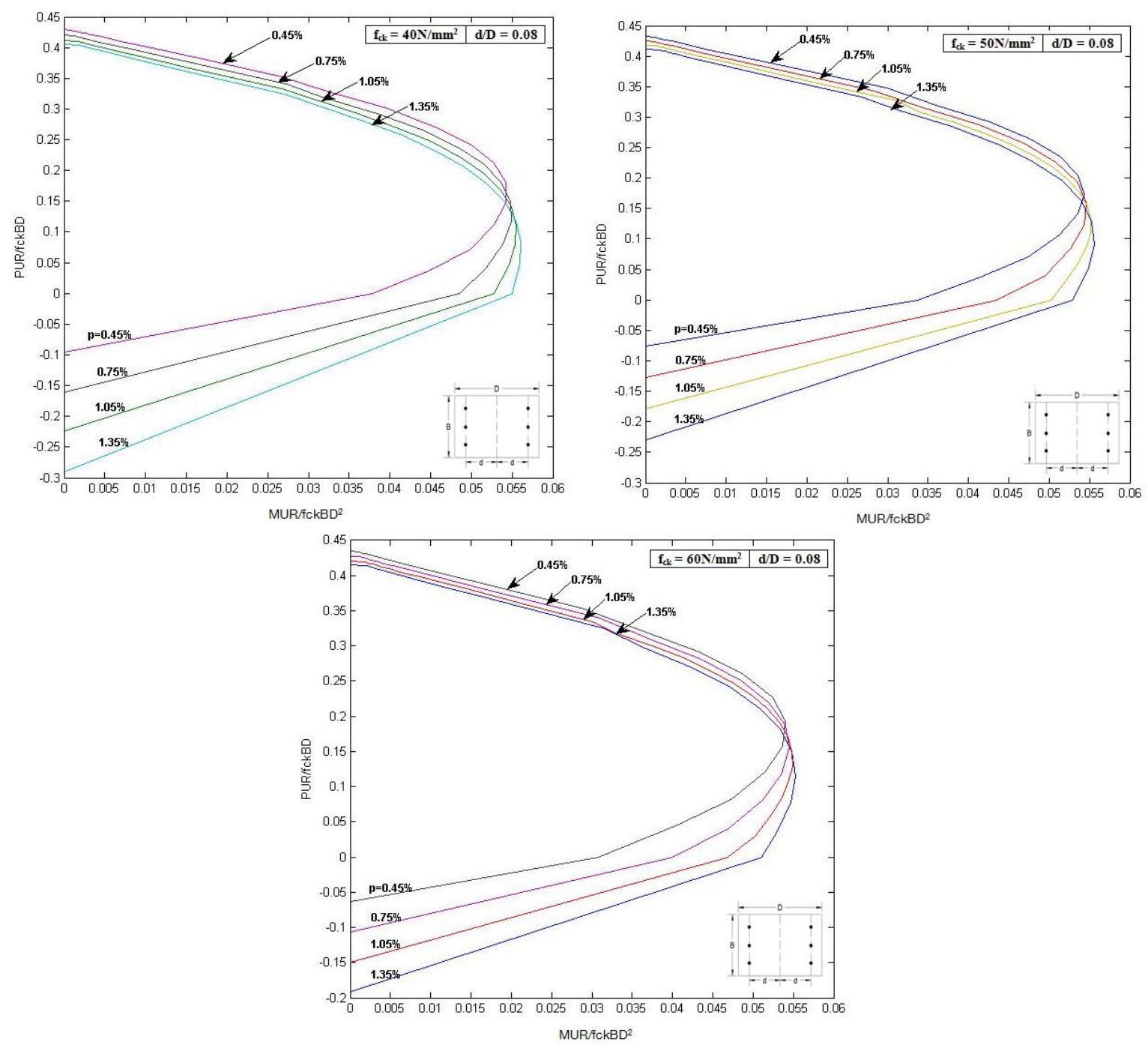

3d. $\left(\frac{M_{U R}}{f_{c k} B D^{2}}, \frac{P_{U R}}{f_{c k} B D}\right)$ Interaction curves with $\mathrm{d} / \mathrm{D}=0.08$ and varying fck

Fig.3. Sample interaction curves developed for prestressed concrete columns with high tensile steel bars

\section{Summary and Discussions}

a) Bars and cold drawn wires

Referring to the interaction charts for prestressed concrete columns with cold drawn wires, bars have more axial load capacity [1]. Whereas, comparing the maximum moment capacities, the difference is very less and is almost the same. But the moment in pure bending case shows slight decrease in bars than wires.

Comparing charts for bars and wires having $\mathrm{d} / \mathrm{D}=0.08, \mathrm{D} / \mathrm{B}=3, f_{c k}=50 \mathrm{~N} / \mathrm{mm}^{2}$ and $p=0.45 \%$, bars show greater axial load capacity, i.e., an excess of $187 \mathrm{kN}$ is seen in bars than wires. But there is a decrease of $34 \mathrm{kNm}$ in the moment capacity at pure bending in bars. For $0.75 \%$ steel an increase of $305 \mathrm{kN}$ is obtained for bars. The decrement in moment is $34 \mathrm{kNm}$ itself. Thus at higher percentage steel more axial load capacity is shown by bars than wires.

b) Set of curves with $B=230 \mathrm{~mm}, f_{c k}=40 \mathrm{~N} / \mathrm{mm}^{2}, p=1.35 \%$ and varying d/D ratio.

For $\mathrm{d} / \mathrm{D}$ ratios 0 and 0.08 , the moments for corresponding loads give very much closer values showing only a maximum difference of $10-14 \mathrm{kNm}$. Therefore curves with $\mathrm{d} / \mathrm{D}=0$ are neglected. 
c) Set of curves with $B=230 \mathrm{~mm}, f_{c k}=40 \mathrm{~N} / \mathrm{mm}^{2}, \mathrm{~d} / \mathrm{D}=0.08$ and varying percentage steel.

For $0.45 \%$ steel and its immediate increment $0.6 \%$ steel, the moment values show a maximum difference of $24 \mathrm{kNm}$ only. This difference decreases to $4 \mathrm{kNm}$ between $1.2 \%$ and $1.35 \%$ steel. Since the differences in moments are small $0.6 \%, 0.9 \%$ and $1.2 \%$ steel are neglected. Taking the difference in percentage steel as $0.3 \%$ charts are plotted.

The increment in moment with percentage steel is less compared to wires. For wires, the increment in moment between minimum and maximum steel is $160 \mathrm{kN}$. But in bars it is only $74 \mathrm{kN}$. The profile of the curves is similar to wires, i.e., the moment capacity first increases and then decreases with increase in load when two successive percentages of steel are compared. The maximum steel of $1.35 \%$ can be adopted only up to $1000 \mathrm{kN}$ axial load. Beyond that minimum steel has to be chosen.

The axial load capacity shows a decrease of $150 \mathrm{kN}$ with increase in percentage steel from $0.45 \%$ to $1.35 \%$. This decrease is less than half the decrease in wires.

d) Set of curves with $B=230 \mathrm{~mm}, p=1.35 \%, \mathrm{~d} / \mathrm{D}=0.08$ and varying concrete compressive strength.

Increase in compressive strength leads to increase in axial load and moment capacities. Similar to wires, there is an increase of $700 \mathrm{kN}$. Also, an average increase of $60 \mathrm{kNm}$ is obtained in moment capacity. For smaller steel percentages the increase in axial load capacity is $700 \mathrm{kN}$ itself but increase in moment capacity is less.

\section{Conclusions}

1. In this study first; a MATLAB program for developing the interaction curves of prestressed concrete short columns with high tensile steel bars was generated and then the column interaction diagrams for different variables were drawn.

2. Charts are drawn for $0.45 \%, 0.75 \%, 1.05 \%$ and $1.35 \%$ steel.

3. Central prestressing and the maximum limit at half kern distance shows almost similar moment capacities. Also, d/D ratio has no effect on axial load capacity. Therefore charts with central prestressing are neglected.

4. Similar to wires, bars also show a substantial increase of $700 \mathrm{kN}$ with increase in concrete compressive strength.

5. The comparison between interaction curves of high tensile bars and cold drawn wires shows that axial load capacity is higher for bars. Bars have more axial load capacity at higher percentage steel than wires.

6. In case of moment capacities, bars show a slight decrease than in wires. For bars, the increment in moment and decrement in axial load capacities between lowest and highest percentages of steel are almost half of that for wires.

\section{Journals:}

\section{References}

[1] Shinju Sajeev Valaparambil, Sivan. P. P and Sanya Maria Gomez, Development of Interaction Curves for Prestressed Concrete Columns with Cold Drawn Wires, International Journal of Emerging Technology and Advanced Engineering, Volume 4, Issue 9, 2014, 655-662.

\section{Books:}

[2] Dr. Amlan K Sengupta \& Prof. Devdas Menon, Prestressed Concrete Structures (NPTEL, Indian Institute of Technology, Madras).

[3] IS: 1343-1980 - Indian Standard- Code of Practice for Prestressed Concrete (Bureau of Indian Standards, New Delhi, 2003).

[4] IS: 2090 -1983 - Indian Standard-Specification for High Tensile Steel Bars Used in Prestressed Concrete (Bureau of Indian Standards, New Delhi, 1993).

[5] A. E. Naaman, Prestressed Concrete Analysis and Design-Fundamentals (Second edition, Techno Press 3000, USA, 2004).

[6] T. Y. Lin and Ned. H. Burns, Design of Prestressed Concrete Structures (Third edition, Wiley India, New Delhi, 2012).

[7] G. S. Pandit and S. P. Gupta, Prestressed Concrete (First edition, CBS Publishers \& Distributors Pvt. Ltd., New Delhi, 2010). 